\title{
Downregulation of Krüppel-like factor 1 inhibits the metastasis and invasion of cervical cancer cells
}

\author{
BISHENG ZHU $^{1 *}$, QISHENG LIU ${ }^{2 *}$, QI HAN ${ }^{1}$, BOHANG ZENG $^{3}$, JINGQI CHEN $^{3}$ and QIUJU XIAO ${ }^{1}$ \\ ${ }^{1}$ Oncology Department; ${ }^{2}$ Department of Gastroenterology, Xingning Central Hospital, \\ The First Affiliated Hospital of Hubei University of Science and Technology, Xianning, Hubei 437000; ${ }^{3}$ Oncology Department, \\ The Second Affiliated Hospital of Guangzhou Medical University, Guangzhou, Guangdong 510260, P.R. China
}

Received May 4, 2018; Accepted August 8, 2018

DOI: $10.3892 / \mathrm{mmr} .2018 .9401$

\begin{abstract}
Cervical cancer is one of the most common malignancies that seriously threatens women's health. Krüppel-like factors (KLFs) have been reported to be associated with the progression of cervical cancer. The role of KLF1 in cervical cancer, which still remains unclear, was investigated in the present study. The expression of KLF1 was detected in different cervical cell lines by reverse transcription-quantitative polymerase chain reaction (RT-qPCR) and western blotting. Cell proliferation, metastasis and invasion were respectively detected by Cell Counting Kit-8, wound healing and transwell assays. Associated factor expression was also detected by RT-qPCR and western blotting. In addition, the phosphorylation levels of phosphatidylinositol-3-kinase $(\mathrm{PI} 3 \mathrm{~K})$ and protein kinase $\mathrm{B}(\mathrm{Akt})$ were determined by western blot analysis. The results revealed that KLF1 expression was promoted in SiHa, Caski and C4-1 cervical cancer cells. However, KLF1 knockdown suppressed cell proliferation, metastasis and invasion in SiHa cervical cancer cells. KLF1 knockdown also inhibited the expressions of Ki67, metastasis-associated antigen 1 and matrix metalloproteinase (MMP)-2. KLF1 knockdown promoted the expressions of nonmetastatic clone 23 type 1 and tissue inhibitor of metalloproteinase-2, and the expression of MMP-9 was promoted slightly as well. In addition, KLF1 knockdown inhibited the PI3K/Akt signaling pathway. Hence, it was concluded that KLF1 promoted metastasis and invasion via the PI3K/Akt signaling pathway in cervical cancer cells.
\end{abstract}

Correspondence to: Dr Bisheng Zhu, Oncology Department, Xingning Central Hospital, The First Affiliated Hospital of Hubei University of Science and Technology, 228 Jinggui Road, Xianan, Xianning, Hubei 437000, P.R. China

E-mail: bishengz_zbs@163.com

*Contributed equally

Key words: Krüppel-like factor 1, metastasis, invasion, cervical cancer, phosphatidylinositol-3-kinase, protein kinase B

\section{Introduction}

Cervical cancer, a malignant tumor that occurs in the cervical epithelium, is one of the most common malignancies that seriously threatens women's health worldwide(1). It is regarded as the most serious malignancy in women reproductive system $(2,3)$, with the annual number of newly diagnosed patients and deaths being approximately 529,800 and 275,100 cases. Noticeably, over $85 \%$ of cervical cancer patients and deaths cause by it are in developing countries (4). The 5-year survival rates of patients who have with early-onset cervical cancer and without pelvic lymph node metastasis ranges from 85 to $90 \%$. Once regional lymph node metastases occurs, the 5-year survival rates drop to 30 to $60 \%$ (5). However, according to the cancer's pathophysiological characteristics, cervical cancer is prone to re-occurrence and metastasize $10-15 \%$ of patients with cervical cancer still show recurrence and metastasis even if the pathological examination shows no sign of lymph node metastasis (6). Some cervical cancer tumor cells is strongly invasive, which would seriously affect the prognosis of patients (7).

It has been reported that the incidence of cervical cancer was associated with abnormal expression of some related molecules including inactivation of various tumor suppressor genes and activation of oncogenes (8). Previous studies have found that transcription factors played important roles in the development and progression of many types of cancers. The activated signal transduction pathways convert extracellular signals into intranuclear signals, and the activation of transcription factors leads to the expression or suppression of downstream genes. These two process eventually changed carcinogenicity. Under both normal development and disease conditions, Krüppel-like factors (KLFs) play roles in the DNA transcription mechanisms, and participate in many biological processes such as cell proliferation $(9,10)$, differentiation $(11)$, migration (12) and apoptosis (13). The KLF gene was first discovered in the developmental regulation factor Krüppel in Drosophila embryos (14). The first mammalian KLF gene, KLF1 or EKLF, was discovered in 1993 (15), followed different homologous genes being subsequently discovered (16). To date, KLF3 (17), KLF4 (18) and KLF5 (19) have been reported to be associated with the occurrence, progression and prognosis of cervical cancer. However, the role of KLF1 in cervical cancer still remains unclear. 
Understanding the molecular mechanisms of the occurrence, development, recurrence and metastasis of cervical cancer is of significance. Such an understanding help guide more in-depth studies on early diagnosis and conduct individualized treatment of cervical cancer. Therefore, we determined to study the role and molecular mechanism of KLF1 on cervical cancer.

\section{Materials and methods}

The cBioPortal survival analysis. The 2-year survival analysis in the cervical cancer patients with or without alterations in query genes of KLF1, was obtained from online analysis of cBioPortal website.

Cell culture. Human cervical cancer cell lines, SiHa (contains a complete HPV16 genome), Caski (HPV16+, contains approximately 400 copies of the HPV16 genome) and C4-1 (HPV18+, contains a complete HPV18 genome) and normal cervical cells were acquired from American Type Culture Collection (ATCC; Guangzhou, China). The normal cervical epithelial cells (HcerEpic) were purchased from BeNa Culture Collection (Jiangsu, China). Cells were cultured in Dulbecco's modified Eagle's medium (DMEM, high glucose) (HyClone; GE Healthcare Life Sciences, Logan, UT, USA) with 10\% (v/v) fetal bovine serum (FBS; Biological Industries, Kibbutz BeitHaemek, Israel) and $100 \mathrm{U} / \mathrm{ml}$ streptomycin and $100 \mu \mathrm{g} / \mathrm{ml}$ penicillin (Biological Industries, Israel) in an incubator with $5 \% \mathrm{CO}_{2}$ at $37^{\circ} \mathrm{C}$. Cells were grown on plastic dishes and prepared for mRNA and protein extraction.

siRNA interference. The sequence of small interfering RNA (siRNA) for KLF1 and non-specific sequence (control siRNA for Mock group) were synthesized by Ribobio (Guangzhou, China). Using Lipofectamine 3000 transfection reagent (Invitrogen, USA), SiHa cells were transfected with $1 \mu \mathrm{g}$ siRNA after the cell confluence reached $70 \%$.

Cell viability detection. Cell Counting Kit-8 (CCK-8; Beyotime Institute of Biotechnology, Haimen, China) was applied to determine cell viabilities. To be more specific, cells $\left(5 \times 10^{3} /\right.$ well) were inoculated in 96-well plates. After being incubated for $24 \mathrm{~h}(\mathrm{~h})$, cells were stained with $20 \mu \mathrm{l}$ staining reagent for $1 \mathrm{~h}$. The optical density (OD) values at $450 \mathrm{~nm}$ were measured by 1500 microplate reader (Thermo Fisher Scientific, Inc., Waltham, MA, USA).

Wound healing assay. Wound healing assay was used to determine cell metastasis abilities. To be more specific, $1 \times 10^{5}$ cells were inoculated in each well of 12-well plates and incubated at $37^{\circ} \mathrm{C}$ for $24 \mathrm{~h}$. Next, the confluent monolayer cells were first scratched gently to form a cell-free area and then cultured in an incubator at $37^{\circ} \mathrm{C}$ for $24 \mathrm{~h}$. Finally, the diameters of cell-free areas were measured under Olympus DSX100 optical microscope (Olympus Corporation, Tokyo, Japan).

Transwell assay. Using 24-well Transwell chambers containing $8-\mu \mathrm{m}$ pore filters (Corning Incorporated, Corning, NY, USA), cell invasion abilities of cervical cancer cells with KLF1 interference were compared to Control and Mock groups. To explain, $5 \times 10^{4}$ cells were cultured in Matrigel GFR (BD Biosciences, Franklin Lakes, NJ, USA)-coated Transwell upper chambers using DMEM culture media. Meanwhile, DMEM culture media containing $10 \%$ FBS was filled in the lower chambers. After the incubation at $37^{\circ} \mathrm{C}$ for $24 \mathrm{~h}$, the bottom membrane was stained with $0.1 \%$ crystal violet at $37^{\circ} \mathrm{C}$ for $30 \mathrm{~min}$. Cell numbers was calculated using Olympus DSX100 optical microscope (Olympus Corporation) with the magnification set at 100-fold.

Reverse transcription-quantitative polymerase chain reaction $(R T-q P C R)$. The mRNA expression levels of KLF1, apoptosis and metastasis related factors were determined by RT-qPCR. Total RNA was extracted from cells with TransZol Up (Beijing Transgen Biotech Co., Ltd., Beijing, China), and cDNA was reverse transcribed by cDNA synthesis SuperMix kit (Beijing Transgen Biotech Co., Ltd.). RT-qPCR amplification was carried out by using LightCycler ${ }^{\circledR}$ SYBR Green I Masters (Roche Diagnostics, Indianapolis, IN, USA) in a LightCycler ${ }^{\circledR}$ 480II System (Roche Diagnostics), and the conditions were set as follows: Initial denaturation at $95^{\circ} \mathrm{C}$ for $5 \mathrm{~min}$ (min), 40 cycles (denaturation at $95^{\circ} \mathrm{C}$ for $15 \mathrm{sec}$, annealing at $57^{\circ} \mathrm{C}$ for $15 \mathrm{sec}$, extension at $72^{\circ} \mathrm{C}$ for $25 \mathrm{sec}$ ) and final extension at $72^{\circ} \mathrm{C}$ for $10 \mathrm{~min}$. The primer sequences of KLF1, Ki67, nonmetastatic clone 23 type 1 (Nm23-H1), metastasis-associated antigen (MTA-1), matrix metalloproteinase (MMP)-2, MMP-9 and tissue inhibitor of metalloproteinase-2 (TIMP-2) are listed in Table I. Gene expression was quantified according to the $2^{-\Delta \Delta \mathrm{Cq}}$ method (20).

Western blot analysis. Cells were rinsed by phosphate-buffer saline (PBS), lysed by Protein Lysis Reagent P0013 (Beyotime, China) for $20 \mathrm{~min}$ and centrifuged on ice at $12,000 \mathrm{x} \mathrm{g}$ for $10 \mathrm{~min}$. The supernatant with proteins was first harvested and then quantified by using BCA protein assay reagent (Beyotime Institute of Biotechnology). Subsequently, total proteins $(20 \mu \mathrm{g} /$ lane) were subjected to $15 \%$ sodium dodecyl sulfate-polyacrylamide gel electrophoresis (SDS-PAGE) and then separated. Next, the gel was transferred onto a piece of polyvinylidene fluoride (PVDF) membranes (Thermo Fisher Scientific, Inc.). The membranes were first blocked using $5 \%$ non-fat dry milk for $1 \mathrm{~h}$ at $37^{\circ} \mathrm{C}$ and then incubated with specific primary antibodies overnight at $4^{\circ} \mathrm{C}$ : Rabbit anti-KLF1 (ab49158, 1:400; Abcam, Cambridge, UK), Ki67 (ab92742, 1:1,000; Abcam), nm23-H1 (ab154547, 1:2,000; Abcam), MTA-1 (ab71153, 1:5,000; Abcam), MMP2 (ab92536, 1:1,000; Abcam), MMP9 (ab38898, 1:1,000; Abcam), TIMP-2 (ab180630, 1:1,000; Abcam), phosphatidylinositol-3-kinase (PI3K) (ab133595, 1:2,000; Abcam), p-PI3K (ab182651, 1:1,000; Abcam), protein kinase B (PKB or Akt) (ab8805, 1:500; Abcam), p-Akt (ab38449, 1:1,000; Abcam) and GAPDH (ab9485, 1:2,000; Abcam). Subsequently, the membranes were probed with Goat Anti-Rabbit IgG H\&L (HRP) secondary antibody (ab6721, 1:5,000; Abcam) for $1 \mathrm{~h}$ at $37^{\circ} \mathrm{C}$. The immunoblots were visualized by GE ECL (enhanced chemiluminescence) Start Detection reagents (GE Healthcare Life Sciences, Little Chalfont, UK). Digital images of immunoreactive bands were obtained by a Bio-Rad ChemiDoc XRS densitometry with Image Lab ${ }^{\text {TM }}$ Software no. 1708265 (Bio-Rad Laboratories, Inc., Hercules, CA, USA). 
Table I. Primer sequences applied in the present study.

\begin{tabular}{lll}
\hline Name & Type & \multicolumn{1}{c}{ Sequence (5'-3') } \\
\hline GAPDH & $\begin{array}{l}\text { Forward } \\
\text { Reverse }\end{array}$ & $\begin{array}{l}\text { CCATCTTCCAGGAGCGAGAT } \\
\text { TGCTGATGATCTTGAGGCTG }\end{array}$ \\
KLF1 & $\begin{array}{l}\text { Forward } \\
\text { Reverse }\end{array}$ & AAAGAGGACGATGAGACCCAAAAGC \\
& ATCCAACAAGG \\
Ki67 & Forward & TCAAAAGGAGTGGCGGAGAT \\
& Reverse & AAAACCTCCCCATTGACACG \\
nm23-H1 & Forward & GGGCTGAATGTGGTGAAGAC \\
& Reverse & GAAACCACAAGCCGATCTCC \\
MTA-1 & Forward & CTACGACCCACAGCAGAAGA \\
& Reverse & TGGTCGATCTGCTTGTCTGT \\
MMP-2 & Forward & CAGCCCTGCAAGTTTCCATT \\
& Reverse & GTTGCCCAGGAAAGTGAAGG \\
MMP-9 & Forward & GAGACTCTACACCCAGGACG \\
& Reverse & GAAAGTGAAGGGGAAGACGC \\
TIMP-2 & Forward & TTCAAAGGGCCTGAGAAGGA \\
& Reverse & TCAGGCTCTTCTTCTGGGTG
\end{tabular}

KLF1, Krüppel-like factor 1; nm23-H1, nonmetastatic clone 23 type 1; MTA, metastasis-associated antigen; MMP, matrix metalloproteinases; TIMP, tissue inhibitor of metalloproteinase-2.

Statistical analysis. Statistical analysis was carried out using SPSS 22.0 (IBM Corp., Armonk, NY, USA). All data were presented as the mean \pm standard deviation. At least three repeated experiments were performed in each group. Significance differences were analyzed by one-way analysis of variance with Dunnett's post hoc test. The Kaplan Meier survival analysis with a log-rank test was used to draw the survival curve. $\mathrm{P}<0.05$ was considered to indicate a statistically significant difference.

\section{Results}

The expression levels of KLF1 in cervical cancer patients and cell lines. According to the online analysis of the cBioPortal website, there was no significant difference on the survival curves between cervical cancer cases with or without alterations in query genes $(\mathrm{P}=0.392)$ in 2 years. However, it could be seen from the figure that the survival rate was increased when KLF1 was up-regulated. Note that the results of this analysis were only for reference as discrepancies may exist from the experimental results (Fig. 1A).

The mRNA and protein levels of KLF1 in different cervical cancer cell lines were compared with normal cervical epithelial cells using RT-qPCR and western blot assays. The results demonstrated that both the mRNA and protein expression levels of KLF1 increased significantly in the 3 cervical cancer cell lines (SiHa, Caski and C4-1 cells), compared with those in normal cervical epithelial cells $(\mathrm{P}<0.01$; Fig. 1B and C). Among all detected cells, KLF1 in $\mathrm{SiHa}$ cell lines had the expression levels among others. Such a results guided us to perform following KLF1-silencing experiments on SiHa cells.
KLF1 interference inhibited cell proliferation, metastasis and invasion abilities of cervical cancer cells. The transfection effect of KLF1-siRNA in SiHa cervical cancer cells was evaluated by RT-qPCR and western blot assays. The results demonstrated that both mRNA and protein levels of KLF1 decreased remarkably in KLF1-siRNA group, compared with Control and Mock groups ( $\mathrm{P}<0.01$; Fig. 2).

To investigate the effect of KLF1 on cervical cancer cell proliferation, we detected cell proliferation abilities using CCK8 assay. The cell proliferation abilities were inhibited in KLF1-siRNA group in a time-dependent (12, 24 and $48 \mathrm{~h}$ ) manner, with significant differences shown at 24 and $48 \mathrm{~h}$ $(\mathrm{P}<0.05$; Fig. 3A). The effect of KLF1 on cell metastasis and invasion abilities of cervical cancer cells was determined by using wound healing and transwell assays. The wound healing and invasion rates were inhibited significantly when KLF1 was knocked down in SiHa cervical cancer cells, compared with Control and Mock groups ( $\mathrm{P}<0.05$; Fig. 3B-E).

KLF1 interference influenced the expression levels of cell proliferation and metastasis-related factors. The expression levels of cell proliferation and metastasis-related factors such as Ki67, Nm23-H1, MTA-1, MMP-2, MMP-9 and TIMP-2 were respectively detected by RT-qPCR and western blot assays. The results showed that both the mRNA and protein expression levels of Ki67 decreased significantly when KLF1 was silenced. However, the mRNA and protein expression levels of Nm23-H1 was increased significantly $(\mathrm{P}<0.01$; Fig. 4A, B and E). In addition, while the mRNA and protein levels of both MTA-1, MMP-2 decreased significantly when KLF1 was silenced, those of MMP-9 was decreased slightly, and those of TIMP-2 was increased significantly $(\mathrm{P}<0.05$; Fig. 4C-E).

KLF1 interference inhibited the activation of PI3K/Akt signaling pathway. To understand the functional mechanism of KLF1 on cell proliferation, metastasis and invasion abilities of cervical cancer cells, we studied the relation between KLF1 and PI3K/Akt signaling pathway. We observed that the phosphorylation levels of PI3K and Akt proteins declined remarkably in KLF1-siRNA group, compared with Control and Mock groups $(\mathrm{P}<0.01$; Fig. 5).

\section{Discussion}

In many developing countries, the early detection strategies for cancer still face many problems. Cervical cancer is still relatively rampant is one of the leading causes of death among women in developing countries (21). Approximately $90 \%$ of cancer deaths are caused by metastases (22), such a figure makes tumor metastasis a critical cause of deaths among cancer patients.

KLFs take part in cell cycle, differentiation, tumor formation. Particularly, in cancers, KLFs function to enhance or inhibit the cell cycle of many types of cells, (19). In this research, we studied whether KLF1 functioned in cervical cancer cells. Although the data from cBioPortal online analysis showed no significant difference in terms of the survival curves between cervical cancer cases with and without alterations in query genes within 2 years, a previous 
A

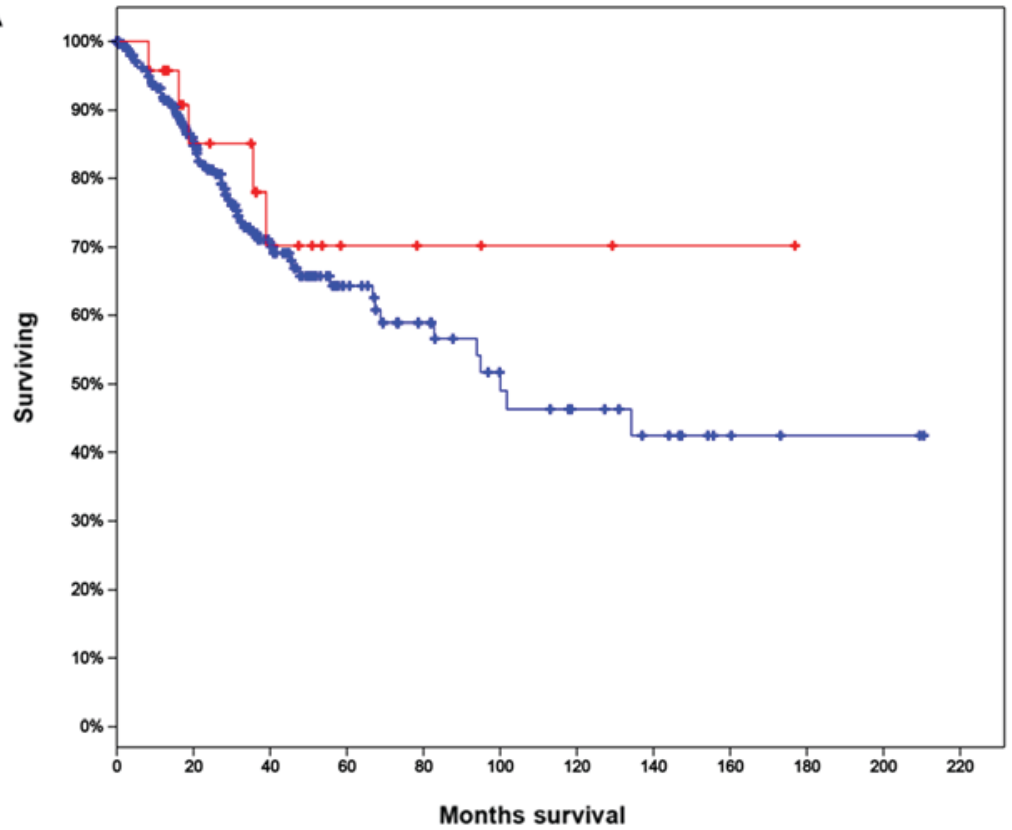

Cases with Alteration(s) in Query Gene(s) - Cases without Alteration(s) in Query Gene(s) Log rank test P-value: 0.392
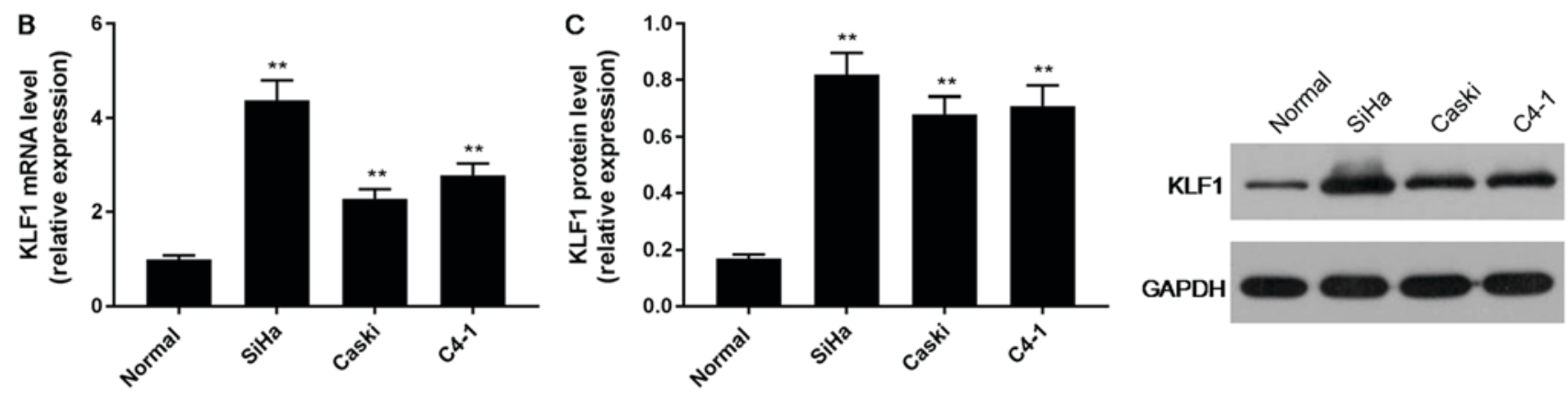

Figure 1. Expression levels of KLF1 in cervical cancer patients and cell lines. (A) The online survival analyses of cervical cancer cases, with and without alterations in query genes, on cBioPortal website. (B) The mRNA levels of KLF1 increased significantly in cervical cancer cell lines (SiHa, Caski and C4-1). (C) The protein levels of KLF1 increased significantly in cervical cancer cell lines (SiHa, Caski and C4-1). ${ }^{* *} \mathrm{P}<0.01$ vs. normal cells. KLF1, Krüppel-like factor 1 .
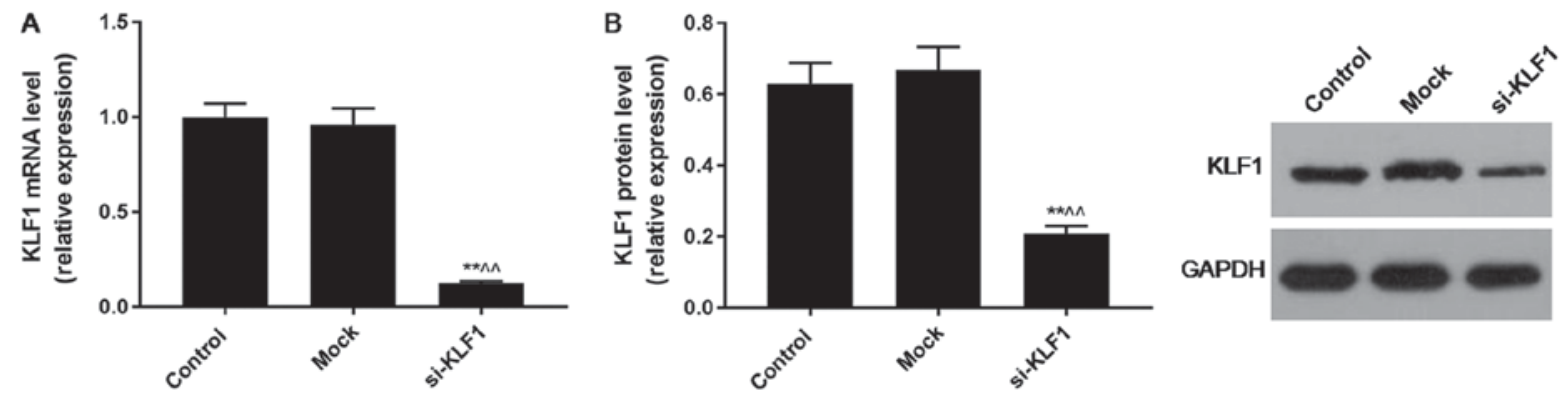

Figure 2. Transfection effect of KLF1-siRNA in SiHa cervical cancer cells. The (A) mRNA and (B) protein levels of KLF1 decreased significantly in the KLF1-siRNA group. ${ }^{* *} \mathrm{P}<0.01$ vs. Control group; ${ }^{\wedge} \mathrm{P}<0.01$ vs. Mock group. KLF1, Krüppel-like factor 1 ; si-/siRNA, small interfering RNA.

study documented that KLF1 mRNA expression was elevated cervical cancer tissues (19). Moreover, we found that KLF1 increased significantly in cervical cancer cells such as $\mathrm{SiHa}$, Caski and C4-1 cells, particularly, in SiHa cells. The small size enrolled in the survival curves (cases with alteration, 20; cases without alteration, 284) may lead to the difference between survival curves and our results. In this study, cell viability, metastasis and invasion abilities were inhibited significantly when KLF1 was silenced in SiHa cells.
The expression of Ki67 have been reported to be directly correlated with the severity of cervical lesions $(23,24)$. Essentially, Ki67 is an nuclear antigen, precisely, it is a non-histone protein located in the nucleus (25). As an important indicator pointing to the activity of tumor cells, Ki67 is actively expressed at each stage of cell division. Consistently, we found that Ki67 actively expressed in cervical cancer cells, and that the expression of Ki67 was down-regulated when KLF1 was knocked down. 


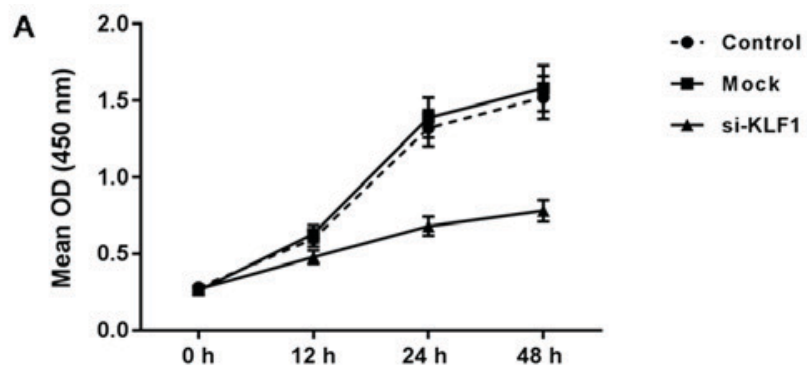

B

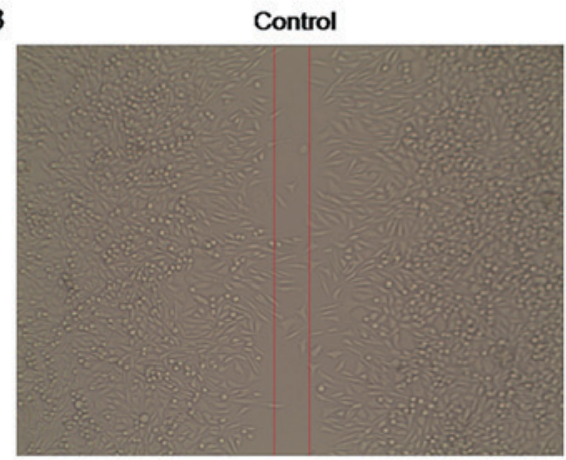

Mock

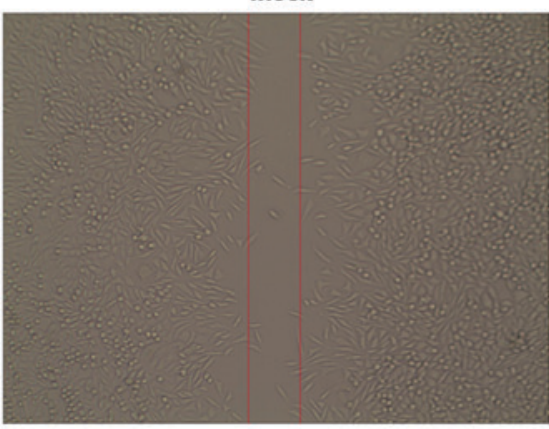

si-KLF1

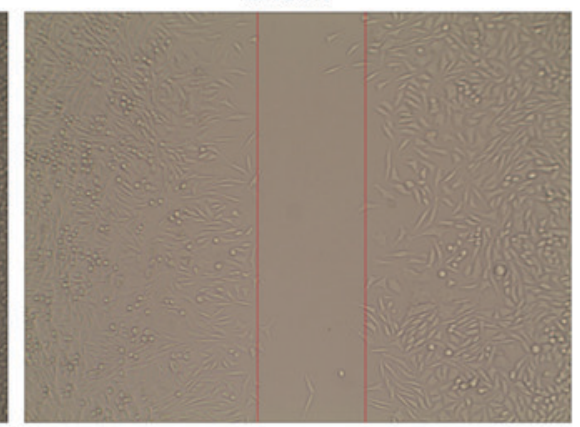

C

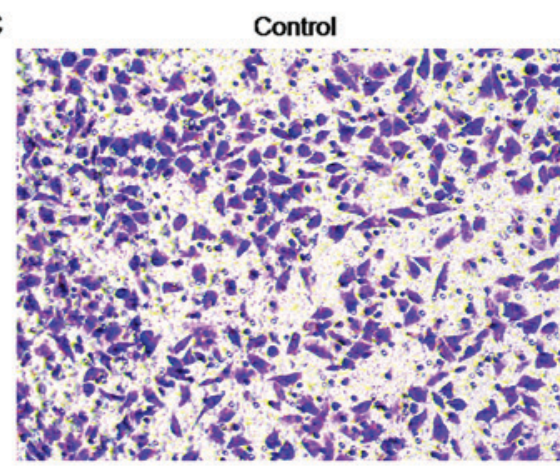

Mock

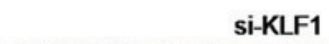

D
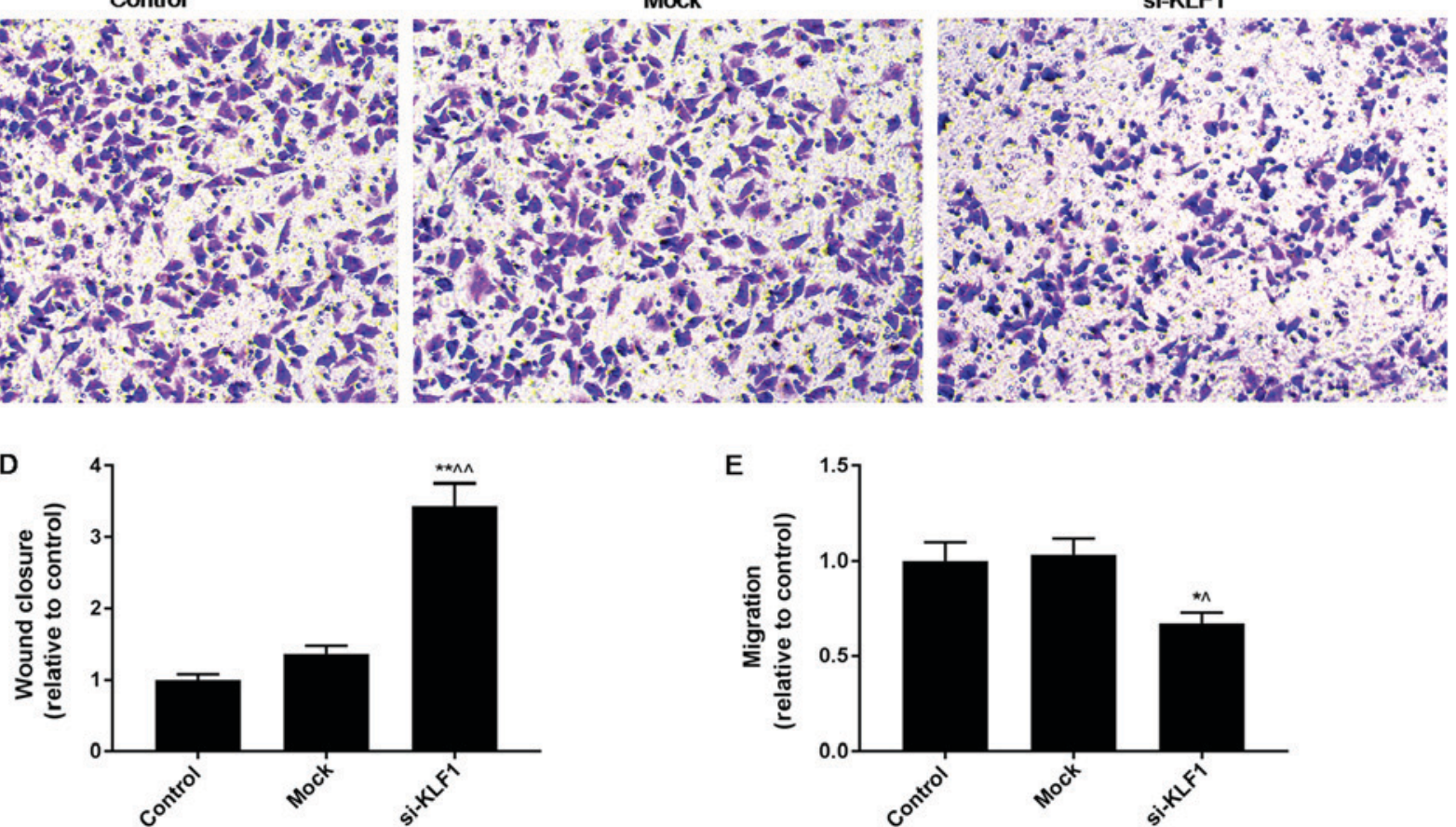

Figure 3. KLF1 interference inhibits the cell proliferation, metastasis and invasion abilities of cervical cancer cells. (A) Cell proliferation abilities were inhibited in the KLF1-siRNA group in a time-dependent manner (12,24 and $48 \mathrm{~h}$ ). (B and D) Using wound healing assays, the cell metastasis ability of cervical cancer cells was revealed to be inhibited in the KLF1-siRNA group. (C and E) The cell invasion ability of cervical cancer cells was inhibited, as determined by a transwell assay. Magnification, $\mathrm{x} 100 .{ }^{*} \mathrm{P}<0.05$ and ${ }^{* *} \mathrm{P}<0.01$ vs. Control group; ${ }^{\wedge} \mathrm{P}<0.05$ and ${ }^{\wedge} \mathrm{P}<0.01$ vs. Mock group. KLF1, Krüppel-like factor 1 ; si-/siRNA, small interfering RNA; OD, optical density.

Tumor metastasis is a complex process in which multiple pathways, steps and molecules are involved. Finding and identifying key regulatory molecules in this process is of great significance in the prevention and treatment of tumors in clinic. Nm23-H1 has diverse functions in the metastasis of many cancers which including cervical cancer (26). Nm23-H1 knockdown has been reported to be able to promote $(27,28)$ or inhibit (29) cell invasion of cervical cancer. In our study, KLF1 knockdown promoted Nm23-H1 expression. MMPs could degrade extracellular matrix of invaded tissues and is critical for tumor metastasis (30-32). Our research showed that KLF1 knockdown inhibited MMP-2 expression. Nevertheless, the expression of MMP-9 remained stable under the interference of KLF1 knockdown. Some other signal molecules (not identified in this study) may also contribute to the regulation the progression of cervical cancer. In addition, our results showed that metastasis-associated antigen MTA was promoted, and that TIMP-2, the specific inhibitor of MMPs (33-35), was 


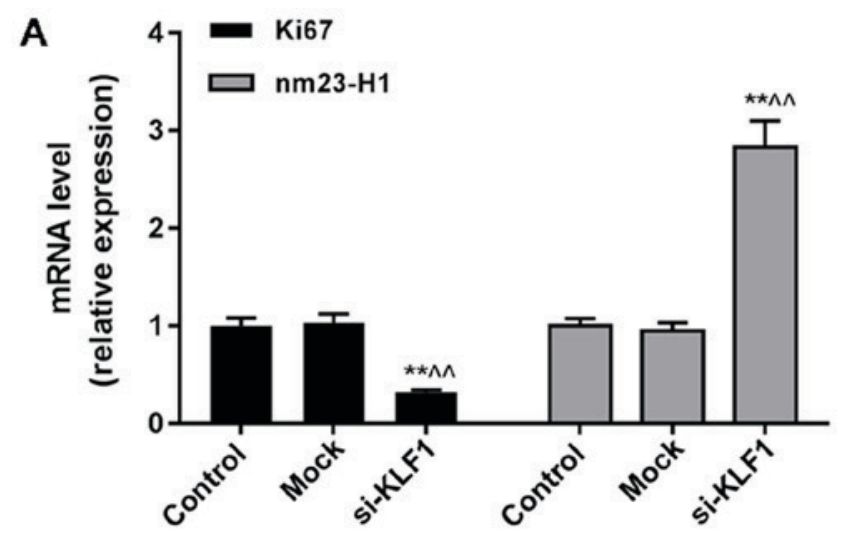

E
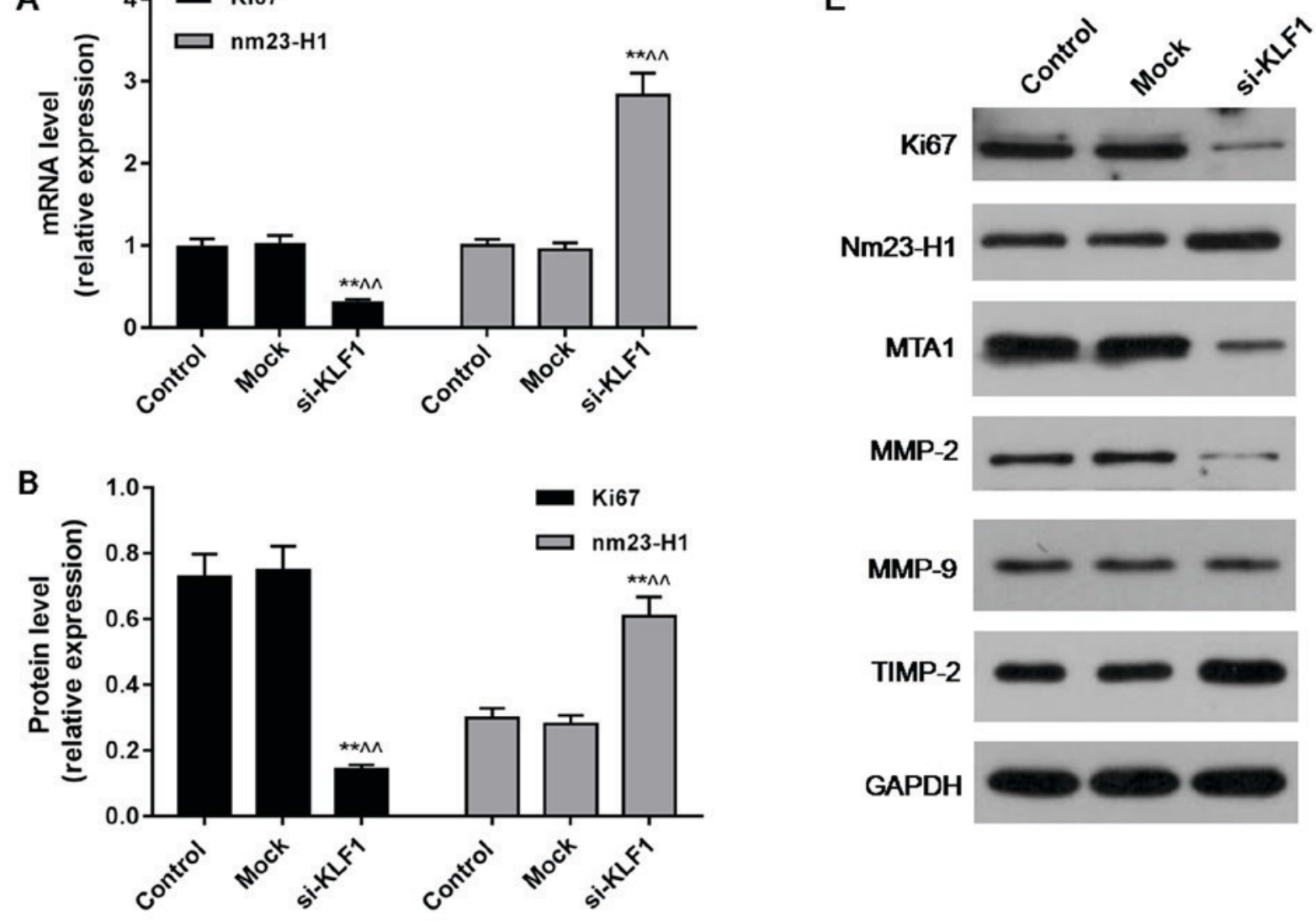

MMP-2

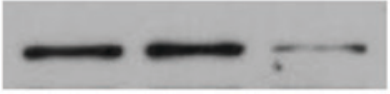

C
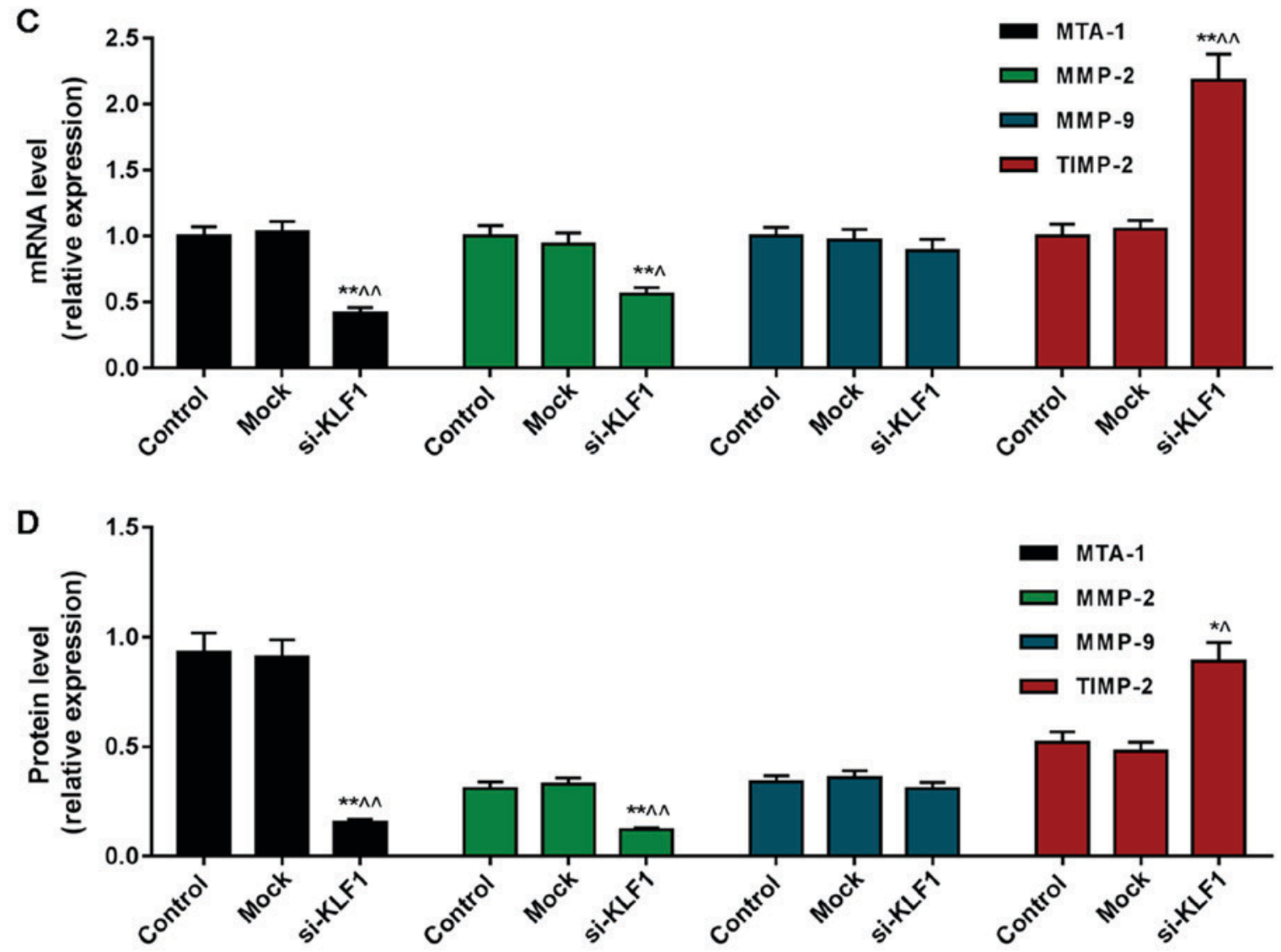

Figure 4. KLF1 interference influences the expression levels of cell proliferation and metastasis-associated factors. (A) The mRNA levels of Ki67 decreased, and nm23-H1 increased when KLF1 was silenced. (B and E) The protein levels of Ki67 decreased, and nm23-H1 increased when KLF1 was silenced. (C) The mRNA levels of MTA-1, MMP-2, MMP-9 and TIMP-2 were detected by reverse transcription-quantitative polymerase chain reaction. (D and E) The protein levels of MTA-1, MMP-2, MMP-9 and TIMP-2 were detected by western blotting. ${ }^{*} \mathrm{P}<0.05$ and ${ }^{* * *} \mathrm{P}<0.01$ vs. Control group; ${ }^{\wedge} \mathrm{P}<0.05$ and ${ }^{\wedge} \mathrm{P}<0.01$ vs. Mock group. KLF1, Krüppel-like factor 1; si-/siRNA, small interfering RNA; nm23-H1, nonmetastatic clone 23 type 1; MTA, metastasis-associated antigen; MMPs, matrix metalloproteinases; TIMP, tissue inhibitor of metalloproteinase-2. 

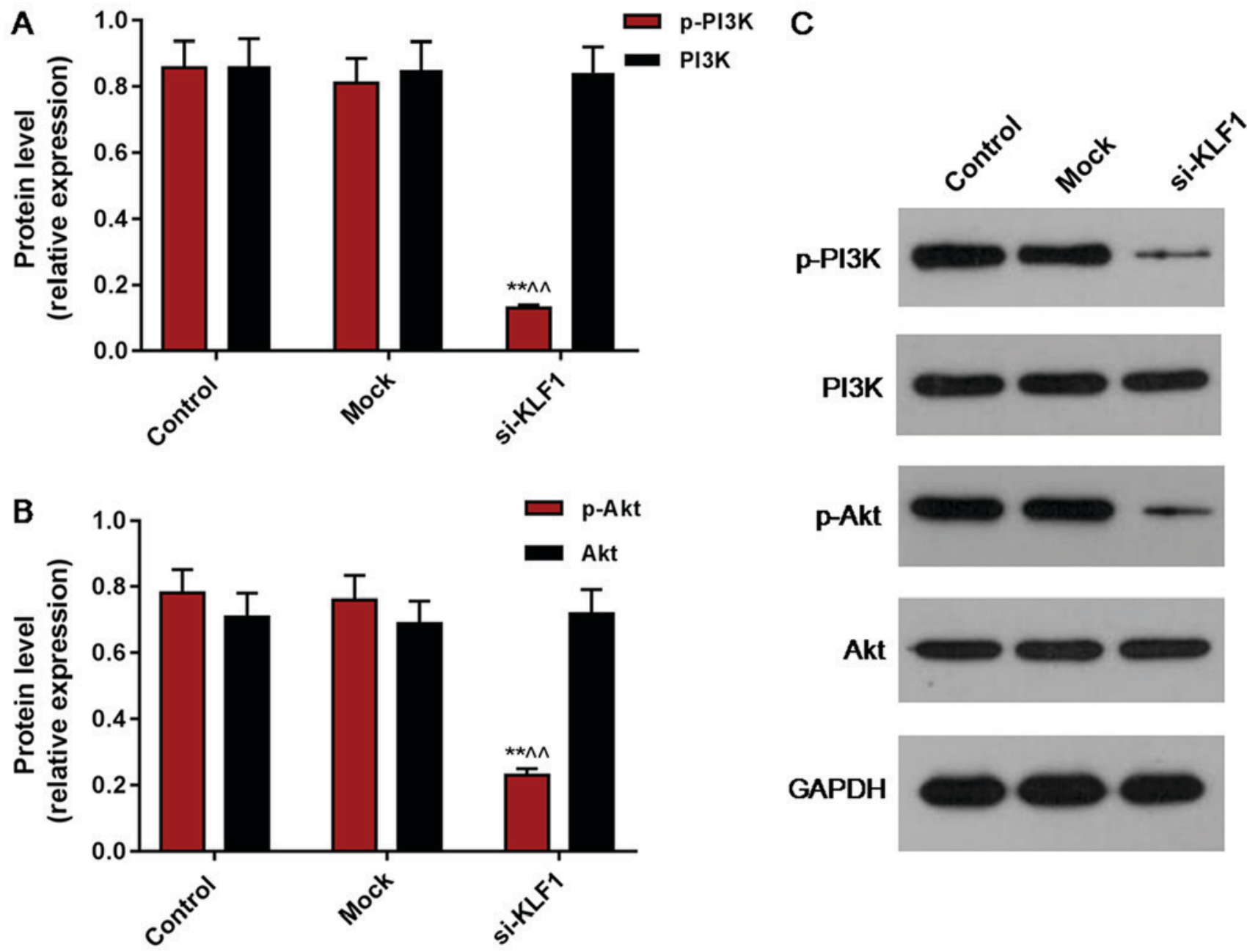

p-Akt

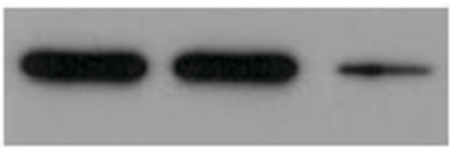

Akt

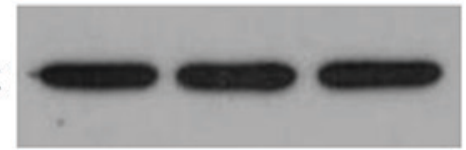

GAPDH

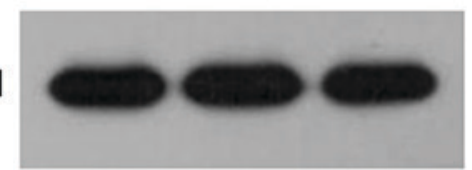

Figure 5. KLF1 interference inhibits the activation of the PI3K/Akt signaling pathway. The phosphorylation levels of (A and C) PI3K and (B and C) Akt proteins declined significantly in the KLF1-siRNA group. ${ }^{* *} \mathrm{P}<0.01$ vs. Control group; ${ }^{\wedge} \mathrm{P}<0.01$ vs. Mock group. KLF1, Krüppel-like factor 1 ; si-/siRNA, small interfering RNA; PI3K, phosphatidylinositol-3-kinase; Akt, protein kinase B; p-, phosphorylated.

inhibited by KLF1 knockdown. Therefore, we confirmed that KLF1 contributed to the inhibition of cervical cancer cell invasion and migration.

Being an important signaling pathway, PI3K signaling is involved in the regulation of cell proliferation, differentiation, apoptosis and it also has many other functions $(36,37)$. Recent studies have found that the signaling pathway composed of PI3K and its downstream protein Akt was closely related to the development of tumors in human body $(38,39)$. Mutations or abnormalities in some components of the signaling pathway can not only lead to the malignant transformation of the cell, but also to the migration of tumor cells, tumor angiogenesis and degradation of the extracellular matrix $(40,41)$. Previous report has found that PI3K/Akt pathway was related to cell proliferation and the invasion of cervical cancer cells (42). The knockdown of KLF1 was found inhibiting the activation of PI3K/Akt pathway in our study, and such a phenomenon indicated that KLF1 promoted metastasis and invasion of cervical cancer via PI3K/Akt pathway.

In conclusion, KLF1 promotes metastasis and invasion via PI3K/Akt pathway in cervical cancer cells. However, the understanding of the function of the KLFs family is limited at present. Therefore, further researches on investigating the role of KLF1 in the pathogenesis of cervical cancer was required and the outcomes of such researches will provide new diagnosis markers and possible therapeutic targets for cervical cancer.

\section{Acknowledgements}

Not applicable.

\section{Funding}

No funding was received.

\section{Availability of data and materials}

The datasets used and/or analyzed during the current study are available from the corresponding author on reasonable request.

\section{Authors' contributions}

BiZ, QL and JC conceived and designed the study. QH, BoZ and QX acquired, analyzed and interpreted the data. BoZ and 
JC drafted the manuscript and critically revised it for important intellectual content. All authors gave final approval of the version to be published. QH and QX agreed to be accountable for all aspects of the work in ensuring that questions related to the accuracy or integrity of the work are appropriately investigated and resolved. All authors read and approved the final manuscript.

\section{Ethics approval and consent to participate}

Not applicable.

\section{Patient consent for publication}

Not applicable.

\section{Competing interests}

The authors declare that they have no competing interests.

\section{References}

1. Castellanos MR, Nehru VM, Pirog EC and Optiz L: Fluorescence microscopy of H\&E stained cervical biopsies to assist the diagnosis and grading of CIN. Pathol Res Pract 214: 605-611, 2018.

2. Vineis P and Wild CP: Global cancer patterns: Causes and prevention. Lancet 383: 549-557, 2014.

3. Torre LA, Bray F, Siegel RL, Ferlay J, Lortet-Tieulent J and Jemal A: Global cancer statistics, 2012. CA Cancer J Clin 65: 87-108, 2015.

4. Schwarz C, Pedraza-Flechas AM, Lope V, Pastor-Barriuso R, Pollan M and Perez-Gomez B: Gynaecological cancer and night shift work: A systematic review. Maturitas 110: 21-28, 2018.

5. Delgado G, Bundy B, Zaino R, Sevin BU, Creasman WT and Major F: Prospective surgical-pathological study of disease-free interval in patients with stage IB squamous cell carcinoma of the cervix: A Gynecologic Oncology Group study. Gynecol Oncol 38: 352-357, 1990.

6. U.S. Preventive Services Task Force: Screening for cervical cancer: Recommendations and rationale. Am J Nurs 103: 101-102, 105-106, 108-109, 2003.

7. Screening PDQ and Prevention Editorial B: Cervical Cancer Screening $\left(\mathrm{PDQ}^{\circledR}\right)$ : Health Professional Version. In: PDQ Cancer Information Summaries. National Cancer Institute (US), Bethesda, MD, 2002.

8. Kim JW, Lee CG, Park YG, Kim KS, Kim IK, Sohn YW, Min HK, Lee JM and Namkoong SE: Combined analysis of germline polymorphisms of p53, GSTM1, GSTT1, CYP1A1, and CYP2E1: Relation to the incidence rate of cervical carcinoma. Cancer 88: 2082-2091, 2000.

9. McConnell BB, Klapproth JM, Sasaki M, Nandan MO and Yang VW: Krüppel-like factor 5 mediates transmissible murine colonic hyperplasia caused by Citrobacter rodentium infection. Gastroenterology 134: 1007-1016, 2008.

10. Chanchevalap S, Nandan MO, McConnell BB, Charrier L, Merlin D, Katz JP and Yang VW: Kruppel-like factor 5 is an important mediator for lipopolysaccharide-induced proinflammatory response in intestinal epithelial cells. Nucleic Acids Res 34: 1216-1223, 2006.

11. Parisi S, Passaro F, Aloia L, Manabe I, Nagai R, Pastore L and Russo T: Klf5 is involved in self-renewal of mouse embryonic stem cells. J Cell Sci 121: 2629-2634, 2008.

12. Jia L, Zhou Z, Liang H, Wu J, Shi P, Li F, Wang Z, Wang C, Chen W, Zhang H, et al: KLF5 promotes breast cancer proliferation, migration and invasion in part by upregulating the transcription of TNFAIP2. Oncogene 35: 2040-2051, 2016.

13. Bafford R, Sui XX, Wang G and Conte M: Angiotensin II and tumor necrosis factor-alpha upregulate survivin and Kruppel-like factor 5 in smooth muscle cells: Potential relevance to vein graft hyperplasia. Surgery 140: 289-296, 2006.
14. Pearson R, Fleetwood J, Eaton S, Crossley M and Bao S: Krüppel-like transcription factors: A functional family. Int $\mathrm{J}$ Biochem Cell Biol 40: 1996-2001, 2008.

15. McConnell BB and Yang VW: Mammalian Krüppel-like factors in health and diseases. Physiol Rev 90: 1337-1381, 2010.

16. Dang DT, Pevsner J and Yang VW: The biology of the mammalian Krüppel-like family of transcription factors. Int J Biochem Cell Biol 32: 1103-1121, 2000.

17. Lyng H,Brøvig RS, SvendsrudDH,Holm R, Kaalhus O, Knutstad K, Oksefjell H, Sundfør K, Kristensen GB and Stokke T: Gene expressions and copy numbers associated with metastatic phenotypes of uterine cervical cancer. BMC Genomics 7: 268, 2006.

18. Yang WT and Zheng PS: Krüppel-like factor 4 functions as a tumor suppressor in cervical carcinoma. Cancer 118: 3691-3702, 2012.

19. Marrero-Rodríguez D, Taniguchi-Ponciano K, Jimenez-Vega F, Romero-Morelos P, Mendoza-Rodriguez M, Mantilla A, Rodriguez-Esquivel M, Hernandez D, Hernandez A, Gomez-Gutierrez G, et al: Krüppel-like factor 5 as potential molecular marker in cervical cancer and the KLF family profile expression. Tumour Biol 35: 11399-11407, 2014.

20. Livak KJ and Schmittgen TD: Analysis of relative gene expression data using real-time quantitative PCR and the 2(-Delta Delta C(T)) method. Methods 25: 402-408, 2001.

21. Kanchiku T, Taguchi T and Kawai S: Magnetic resonance imaging diagnosis and new classification of the osteoporotic vertebral fracture. J Orthop Sci 8: 463-466, 2003.

22. Gupta GP and Massagué J: Cancer metastasis: Building a framework. Cell 127: 679-695, 2006.

23. Barré S, Massetti M, Leleu H and De Bels F: Organised screening for cervical cancer in France: A cost-effectiveness assessment. BMJ Open 7: e014626, 2017.

24. Szekerczés T, Galamb Á, Kocsis A, Benczik M, Takács T, Martonos A, Járay B, Kiss A, Jeney C, Nyíri M, et al: Dual-stained cervical cytology and histology with Claudin-1 and Ki67. Pathol Oncol Res: Feb 13, 2018 (Epub ahead of print).

25. Kanthiya K, Khunnarong J, Tangjitgamol S, Puripat N and Tanvanich S: Expression of the p16 and Ki67 in cervical squamous intraepithelial lesions and cancer. Asian Pac J Cancer Prev 17: 3201-3206, 2016.

26. Wang PH, Yang SF, Tseng CJ, Ying TH, Ko JL and Lin LY: The role of lipocalin 2 and its concernment with human nonmetastatic clone 23 type 1 and p53 in carcinogenesis of uterine cervix. Reprod Sci 18: 447-455, 2011.

27. Huang S, Qin J, Chen J, Cheng H, Meng Q, Zhang J, Wang H and $\mathrm{Li} \mathrm{H}$ : Laparoscopic surgery inhibits the proliferation and metastasis of cervical cancer cells. Int J Clin Exp Med 8: 16543-16549, 2015.

28. Wu CH, Lin YW, Wu TF, Ko JL and Wang PH: Clinical implication of voltage-dependent anion channel 1 in uterine cervical cancer and its action on cervical cancer cells. Oncotarget 7: 4210-4225, 2016

29. Wang PH, Ko JL, Yang SF and Lin LY: Implication of human nonmetastatic clone 23 Type 1 and its downstream gene lipocalin 2 in metastasis and patient's survival of cancer of uterine cervix. Int J Cancer 129: 2380-2389, 2011.

30. Kasorn A, Loison F, Kangsamaksin T, Jongrungruangchok S and Ponglikitmongkol M: Terrein inhibits migration of human breast cancer cells via inhibition of the Rho and Rac signaling pathways. Oncol Rep 39: 1378-1386, 2018.

31. Tyszka-Czochara M, Lasota M and Majka M: Caffeic acid and metformin inhibit invasive phenotype induced by TGF- $\beta 1$ in $\mathrm{C}-4 \mathrm{I}$ and $\mathrm{HTB}-35 / \mathrm{SiHa}$ human cervical squamous carcinoma cells by acting on different molecular targets. Int J Mol Sci 19: pii: E266, 2018.

32. Wang Q, Xu H and Zhao X: Baicalin inhibits human cervical cancer cells by suppressing protein kinase C/signal transducer and activator of transcription (PKC/STAT3) signaling pathway. Med Sci Monit 24: 1955-1961, 2018.

33. Wu MH, Lin CL, Chiou HL, Yang SF, Lin CY, Liu CJ and Hsieh YH: Praeruptorin A inhibits human cervical cancer cell growth and invasion by suppressing MMP-2 expression and ERK1/2 signaling. Int J Mol Sci 19: pii: E10, 2017.

34. Yuan Y, Ye HQ and Ren QC: Upregulation of the BDNF/TrKB pathway promotes epithelial-mesenchymal transition, as well as the migration and invasion of cervical cancer. Int J Oncol 52: 461-472, 2018.

35. Zhou WJ, Yang HL, Chang KK, Meng Y, Wang MY, Yuan MM, Li MQ and Xie F: Human thymic stromal lymphopoietin promotes the proliferation and invasion of cervical cancer cells by downregulating microRNA-132 expression. Oncol Lett 14: 7910-7916, 2017. 
36. Chen Y, Sun Z, Qi M, Wang X, Zhang W, Chen C, Liu J and Zhao W: INPP4B restrains cell proliferation and metastasis via regulation of the PI3K/AKT/SGK pathway. J Cell Mol Med 22: 2935-2943, 2018.

37. Dong P, Hao F, Dai S and Tian L: Combination therapy Eve and Pac to induce apoptosis in cervical cancer cells by targeting PI3K/AKT/mTOR pathways. J Recept Signal Transduct Res 38: 83-88, 2018

38. Tamura R, Yoshihara K, Saito T, Ishimura R, Martínez-Ledesma JE, Xin H, Ishiguro T, Mori Y, Yamawaki K, Suda K, et al: Novel therapeutic strategy for cervical cancer harboring FGFR3-TACC3 fusions. Oncogenesis 7: 4, 2018.

39. Zhang W, Xiong Z, Wei T, Li Q, Tan Y, Ling L and Feng X: Nuclear factor 90 promotes angiogenesis by regulating HIF-1 $\alpha$ /VEGF-A expression through the PI3K/Akt signaling pathway in human cervical cancer. Cell Death Dis 9: 276, 2018.
40. Jiang H, Li J, Chen A, Li Y, Xia M, Guo P, Yao S and Chen S: Fucosterol exhibits selective antitumor anticancer activity against HeLa human cervical cell line by inducing mitochondrial mediated apoptosis, cell cycle migration inhibition and downregulation of m-TOR/PI3K/Akt signalling pathway. Oncol Lett 15: 3458-3463, 2018

41. Li A, Gu Y, Li X, Sun H, Zha H, Xie J, Zhao J, Huang M, Chen L, Peng Q, et al: S100A6 promotes the proliferation and migration of cervical cancer cells via the PI3K/Akt signaling pathway. Oncol Lett 15: 5685-5693, 2018.

42. Shi X, Ran L, Liu Y, Zhong SH, Zhou PP, Liao MX and Fang W: Knockdown of hnRNP A2/B1 inhibits cell proliferation, invasion and cell cycle triggering apoptosis in cervical cancer via PI3K/AKT signaling pathway. Oncol Rep 39: 939-950, 2018.

(i) $\Theta$ This work is licensed under a Creative Commons

Attribution-NonCommercial-NoDerivatives 4.0 International (CC BY-NC-ND 4.0) License. 